\title{
GLACIER ADVANCES APPARENT AND REAL
}

A contribution to the discussion

By Dr. R. STREIfF-Becker (Zürich)

THE description in the Fournal of Glaciology, Nos. 19 and 20, 1956, of two extraordinary glacier advances prompts me to make a critical rejoinder, more especially as Dr. K. Bengtson (No. 20, p. 713) expresses the opinion that the advance of the Coleman Glacier must be ascribed to a worsening of weather conditions. Now the disappearance of glacier formations is world-wide, extending from the North Pole to the South Pole, and this would seem to indicate an improvement in weather conditions of cosmic origin. A worsening of weather conditions in such a small area as that of Mount Baker, sufficient to produce the changes seen in the Coleman Glacier, is not very credible. I am inclined to think that we have here a pseudo-advance, which will soon be followed by a correspondingly greater retreat. The general disappearance of glaciers began about thirty years ago. Since then the level of the firn fields in the accumulation region of the alpine glaciers has fallen by 50 to $80 \mathrm{~m}$. Only a long series of climatically unfavourable years could restore this lost mass : two or three such years would not be sufficient to produce any lasting glacier advance.

The sudden advance of the Kutiàh Glacier in the Karakoram-Ladakh region has been described by the Italian geologist Professor A. Desio (in No. I6 of the Fournal, p. 383, 1954). Here he certainly gives the correct explanation: that glacier wastage itself is the cause of the advance, in that subsidence of the middle course of the main glacier has removed support from the bases of the laterally hanging glaciers and caused them to collapse. The enormous mass of ice thus suddenly banked up in the narrow valley, together with much melted snow and ice, moves outwards from the valley like an avalanche. Something similar may have happened to the Nisqually Glacier in the Mount Rainier district. Compare carefully the pictures in this fournal, No. 19, p. 680, 1956. The firn or accumulation area (crucial for a genuine advance) shows no increase in extent; on the contrary, rather it has decreased. In the picture taken in $195 \mathrm{I}$ (above, right) a small nunatak can be seen as a short black line, which in the picture of 1955 is somewhat thicker; and below, as a small black point, a new nunatak even can be perceived. The level of the firn area has consequently sunk slightly, and the advance of the glacier tongue cannot be a genuine one, consequent upon worsening weather conditions.

In the Zeitschrift für Gletscherkunde, No. 12, p. I8-19, 1938, I postulated slow wave movements through the firn mass, caused by fluctuating pressure conditions in the firn, for instance, through loading of the "flowable" firn layers near the bottom by excessive amounts of winter snow; or, in hot summers, through the pressure of high-lying steep firn fields which have become detached from the frozen bottom. On Mount Baker, it is also possible that rising volcanic warmth heats the rock bottom under the higher firn fields, so that these are detached and their gravitational pressure causes the advance of the glacier tongues below.

We who are interested in glacier research should pay very close attention to the state of the accumulation area, i.e. of the highest firn fields, since genuine and enduring glacier advances can only originate there. Unfortunately the statistics of glacier advance and retreat are not always quite reliable, since it occasionally happens that remains of recent winter snow, lying in front of the glacier tongue, are measured as part of the glacier, and thus advances are erroneously reported, where possibly there are disguised retreats.

MS. received I 2 Fanuary 1957 